\title{
Development and challenge of paste technology in China
}

\author{
Aixiang Wu University of Science and Technology Beijing, China \\ Haiyong Cheng University of Science and Technology Beijing, China \\ Ying Yang University of Science and Technology Beijing, China \\ Lianfu Zhang University of Science and Technology Beijing, China
}

\begin{abstract}
As paste technology can effectively ensure safe mining conditions and realize green mining, it has been popularized and widely applied in China in recent years. Meanwhile, with the development of intelligent control, precise preparation and personalized filling, studies on paste technology in China have also been deepened. In this paper, the basic concepts and characteristics of paste technology were introduced, and the development of paste technology in China was analyzed statistically. It systematically analyzed the latest research progress in thickening dewatering of unclassified tailings, pipeline transportation of structure flow, multi-field influence in stopes, development of new materials and construction of paste engineering laboratory. The practical effects of paste technology in underground backfill and surface deposition were also introduced. In the future, paste technology will achieve great breakthroughs by digitization and intelligence and realize adaptive control of concentration, precision preparation of paste, personalized filling of stopes and $3 D$ and modular design and assembly of system, leading mining industry in China to the path of green development.
\end{abstract}

\section{Introduction}

Since reform and opening-up, China has achieved great economic progress, with an average growth rate of 9\% in the last decade, and has become the second largest economy in the world (Lu, 2011). In China's economic development, mining has always served as the pillar industry (Qian et al., 2008). However, the rapid growth of mining industry also leads to severe problems in environmental protection, production safety and resource utilization (Xu et al., 2012; Chen and Liu, 2009; Chen and Zhang, 2005).

In 2005, the concept of "green mining" was firstly proposed by China Mining Association. For its implementation, the State Administration of Taxation and the Ministry of Land and Resources in China co-announced a $50 \%$ reduction on resource tax for the mines under buildings, roads and water bodies and which apply backfill method. Besides, the Environmental Protection Tax Law of the People's Republic of China declares tailings discharge tax be 15 RMB yuan per ton from Jan 1st, 2018. With more laws and regulations having been issued, the concept of green mining is becoming a reality in engineering practices (Yu, 2016; Wang, 2014; Xie et al., 2017; Zhang et al., 2015).

After years of exploration and practices, paste technology have achieved a series of breakthroughs in thickening (Jiao et al., 2011; Wu et al., 2012; Wang et al., 2013; Wang et al., 2011), dewatering, pumping and long-distance pipeline transportation for unclassified tailings (Cui et al., 2013; Wu et al., 2014; Li and Fang, 
2004). Solid tailings have been fully utilized and issues regarding tailings pond discharge safety and environmental pollution have also been dealt with. Furthermore, underground mining safety has been greatly improved for goaf filled with paste. Paste technology is proved to be comprehensively superior in ensuring safety and ecology protection as well as raising profits and working efficiency (Ghirian and Fall, 2013; Wu et al., 2015; Wu et al., 2015; Wang et al., 2014). Therefore, paste technology gains wide applications worldwide and is recognized as one of the promising green mining technologies in the 21st century.

\section{Summary of paste technology}

\subsection{The basic concept of paste}

Paste is defined as a toothpaste-like, no-bleeding structure fluid compounded from multi-scale granular material and water. It is traditionally believed that paste would not isolate, settle or dewater in the ordinary way. Because a wide range of materials can be made into paste, its properties are difficult to quantify due to various material characteristics. There has been extensive research on the definition of paste, especially in terms of yield stress. For instance, Fall classifies the slurry with a yield stress of over $200 \pm 25 \mathrm{~Pa}$ as paste (Fall et al., 2010; Jewell et al., 2002). In China, paste is considered to feature a slump between $15 \sim 25 \mathrm{~cm}$ and a segregation degree below $2 \mathrm{~cm}$ (Liu et al., 2001; Wang et al., 2010). Note that Wu (Wu and Wang, 2015) ${ }^{\mathrm{l}}$ also proposed the bleeding rate of paste to be between 1.5 and $5 \%$.

\subsection{Development of paste technology in China}

In the 1990s, exploration and practices of green mining have been initiated. Paste technology also commenced when Jinchuan Group Co., Ltd built the first paste filling system in 1996 (Li, 2004). Later, the first deep cone thickening paste filling system was built in Huize Lead-zinc Deposit, Yunnan Province, in 2006. The system not only achieved zero discharge of tailings but also pioneered the application of smelting slag in underground filling, which improved the strength of filling body and reduced the discharge of smelting solid waste (Ji and Yan, 2006). Wushan Copper Molybdenum Mine established the first paste discharge system and achieved discharge in low temperature (Wu et al., 2011). Besides, Jiashi Copper Mine set up a rich-clay unclassified tailings paste filling system which later became a demonstration project for domestic equipment (Wu et al., 2014). Until now, Jinxin Polymetallic Mine has constructed a paste filling system with a filling capacity of $500 \mathrm{~m}^{3} / \mathrm{h}$.

The rapid development of paste technology in nonferrous metal, ferrous metal, gold and coal has emerged as a hotspot in mining applications and studies in China. Statistics show that 56 non coal mines and 38 coal mines have applied paste filling technology from 1996 to 2017, as shown in Figure 1.

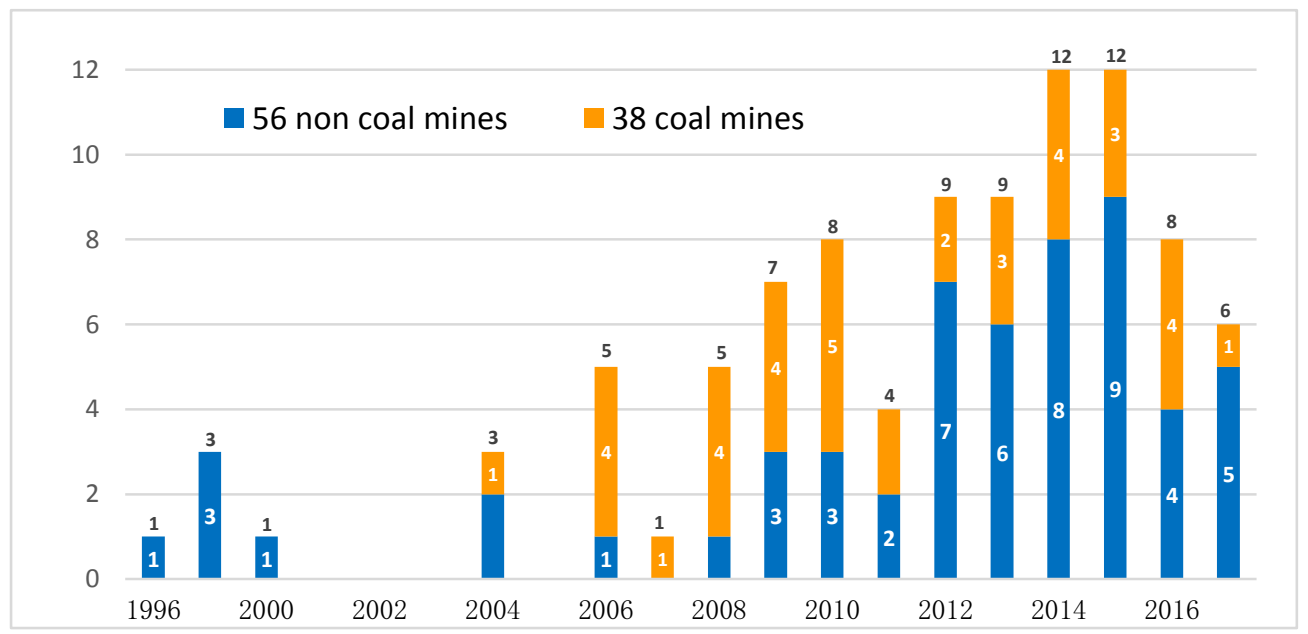

Figure 1 Number of mines which apply paste technology in China (1996 - 2017) 


\subsection{Technical characteristics of paste technology}

Paste filling refers to the transportation of tailings to underground deposits for intended functions. Generally, low concentration tailings slurry is thickened and after mixed with cementing materials and admixtures, turns into paste with specific flow characteristics. Paste is transported into filling stopes by gravity and pumped to fulfill certain functions, as shown in Figure 2. Paste filling mainly includes material storage, filling plan, tailings thickening, paste preparation and pipeline transportation. By efficient and reasonable application of unclassified tailings, the covered area of surface tailings pond could be reduced and environment can be better protected. Furthermore, accurate control of filling body strength obviously improves underground mining safety.

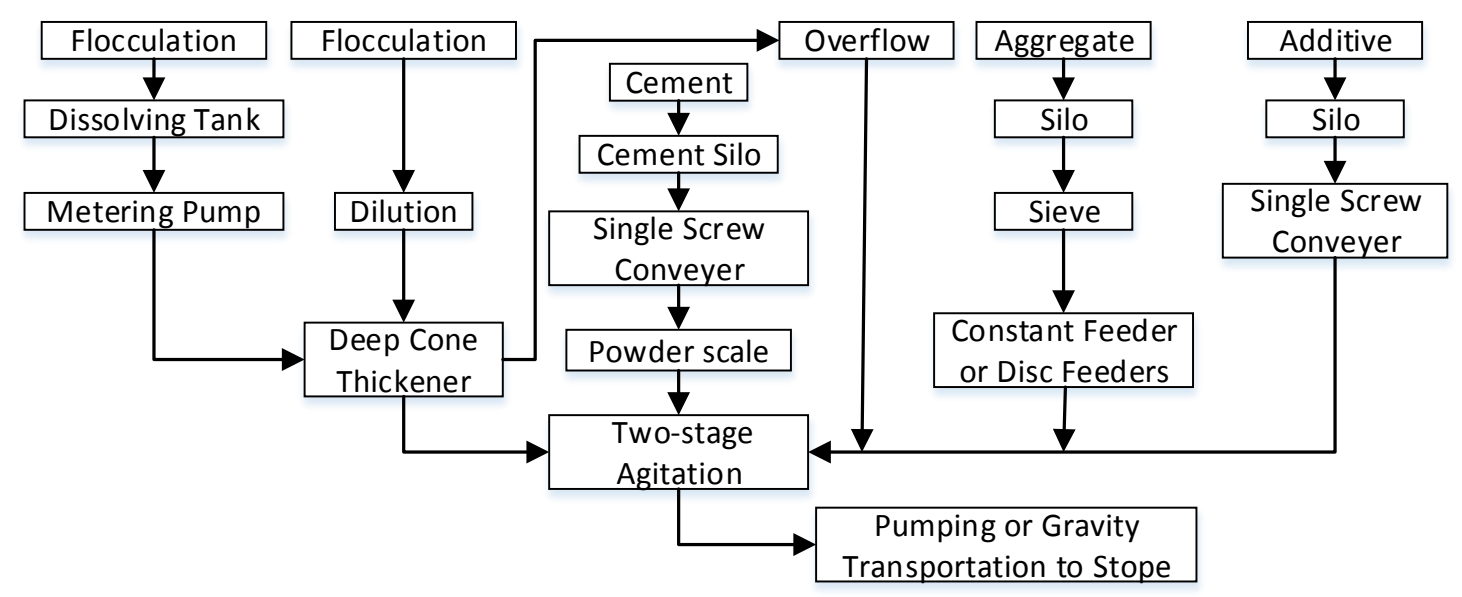

Figure 2 Process flow chart of paste backfill

\section{$3 \quad$ Studies of paste technology in China}

Paste technology is a multidisciplinary system engineering. With the development of science and technology, the research on paste technology has been further developed. This section reviews the studies of paste technology in China in the fields of tailings thickening, paste transportation, paste stope performance, new material research and development and engineering laboratory construction.

\subsection{Tailings thickening}

High concentration slurry of unclassified tailings is the premise of preparing high quality paste. Tailings are usually thickened by gravity thickening and mechanical filtration. After mechanical filtration, the water content of tailings (filter cake) is low and the concentration can reach 80 85\%, which meets the requirement of paste preparation. However, mechanical filtration features high cost, low efficiency and high energy consumption. On the other hand, gravity thickening has rapidly evolved from traditional thickener and high efficiency thickener to deep cone thickener. And the underflow concentration also increased from $40 \sim 60 \%$ to 70 80\%. The relatively convenient deep cone thickening process, with moderate concentration and high efficiency (Wu and Wang, 2015), is currently the mainstream preparation process of paste in China and the world as well.

The thickening degree of tailings determines the quality of paste to a certain extent. In a deep cone thickener, the underflow concentration affects that of the final paste while the dehydration rate affects the handling capacity of the thickening system. Therefore, underflow concentration and the dehydration rate are two key indices of tailings thickening. The addition of flocculant serves to improve the settlement velocity, increase 
both the liquid seepage resistance and the yield stress of the slurry and affect the rotation efficiency of the thickener. Research on torque calculation model of the thickener rake is valuable to optimize the design of power unit and thickener rake.

Thickening experiments of unclassified tailings in China have so far formed a complete hierarchical structure. We have a series of small and dynamic thickening systems $(\Phi 0.1 \sim 0.5 \mathrm{~m} \times h 1.5 \mathrm{~m})$, medium and semiindustrialized deep cone thickening systems $(\Phi 1.375 \mathrm{~m} \times h 2.5 \mathrm{~m})$ as well as large and industrialized deep cone thickening systems $(\Phi 1.0 \mathrm{~m} \times 6.0 \mathrm{~m})$. Using the small and dynamic thickening systems, the experimental design is flexible and the material consumption is low, but the data acquisition is fluctuant and the experiments are not replicable. The medium and semi-industrialized deep cone thickening systems have stable data acquisition and reliable results, but the ratio of height to diameter is small and the experimental range also has some limitations. In comparison, the large and industrialized deep cone thickening systems can realize multi-parameter and continuous monitoring as well as multi-factor and comprehensive analysis, and could serve as industrial guidance. Meanwhile, with the development of computer and numerical simulation, the migration regularity of tailings and flocs in deep cone thickeners becomes increasingly transparent. Using numerical simulation to analyze the internal structure of deep cone thickeners has become important to study the thickening law. Through the establishment of CFD-PBM group balance numerical model, previous research (Ruan, 2015) has preliminarily quantified the flow characteristics of unclassified tailings in deep cone thickeners, and a model of agglomeration-fragmentation of flocs during shear development has been established.

\subsection{Pipeline transportation}

The transportation of paste in pipe is different from that of the traditional two-phase fluid, and is considered as a form of structure flow. Numerous experimental studies have been conducted on pipeline transportation using various techniques, such as Ultrasonic Doppler velocimetry (UDV), laser Doppler velocimetry (LDV) (Liu, 1998; Wang, 1989), nuclear magnetic resonance imaging (MRI), particle tracking velocimetry (PTV) (Wang et al., 2000), and particle image velocimetry (PIV) (Zou, 2016). However, there is still no consensus on the transportation form of paste in pipeline or consensus on the interpretation system for influencing factors and calculation models of paste resistance. It is common to measure the rheological parameters and calculate the resistance along the pipeline. However, accurate calculations are difficult to ensure due to the irreplicable rheological characteristics, the expensive experimental equipment and the high requirements for operation and theoretical analysis.

Based on the theory of two-phase flow, the resistance calculation formula in the early stage includes that of Jinchuan, Changsha Institute of Mining and Metallurgy, Anshan Institute and the empirical formula of Huize. These formulas are based on specific materials and application environment, hence limiting its popularization and application (Wang et al., 2010; Wu and Wang, 2015). Recent research shows that the main factors of paste resistance include concentration, aggregate gradation, density, pipe diameter, flow velocity, additives and so on. Meanwhile, the paste in the pipe also has wall slip and thixotropy behaviours, and can be strongly affected by temperature.

Wu et al. (2016) divided the paste flow zone into the piston-flow zone, the shear-flow zone and the slip-flow zone, established a model for pipeline transportation resistance by considering the effect of pipe-wall slippage and discussed the thickness of slip layer and its influencing factors. Time variability of paste reduces the pipeline resistance and the resistance tends to be steady under constant shear. It is found that paste has obvious temperature effect in the range of $5^{\sim} 50^{\circ} \mathrm{C}$. With temperature increasing, the floc structure in the paste gradually changes to liquid network structure, along with the gradual decrease of yield stress and plastic viscosity as well as the resistance along the pipeline.

The resistance of paste in pipe is influenced by both the material characteristics and the transportation 
conditions and the external fields. Future studies will need to consider the optimized way to construct an "all factors" resistance calculation model for pipeline transportation.

\subsection{Paste stope performance}

Paste stope performance is an important index to evaluate paste filling effect. The focus of studies on the properties of hardened paste gradually shifts from a single mechanical property to multi-field coupling properties. The transportation of paste to stope involves heat transfer, seepage, mechanics, chemical and other processes, as shown in Figure 3.

Multi-field coupling properties of paste feature a high internal relationship. The evolution of paste strength is mainly due to the continuous chemical reaction between the active components in paste and water and the production of a series of hydration products such as C-S-H (Zeng et al., 2010; Li et al., 2009). By affecting the hydration rate of paste and the hydration products, factors such as paste concentration, water-cement ratio, temperature, chemical composition and others influence the internal volume moisture content and pore structure of paste. Finally, a filling body with a certain strength is formed.

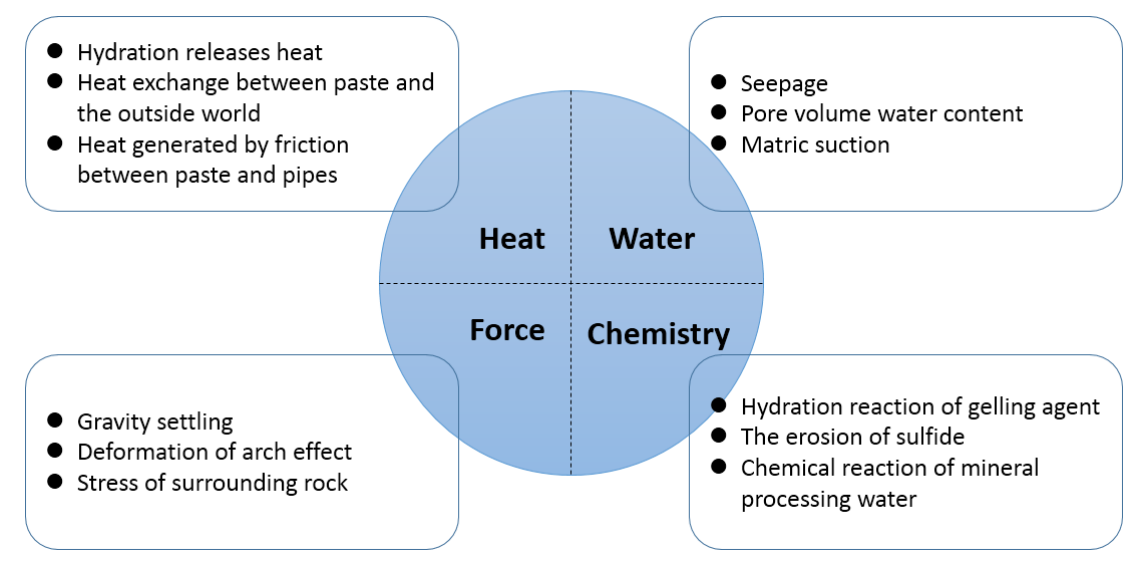

Figure 3 Coupled thermo-hydro-mechanical-chemical behavior of the paste backfill

\subsection{Development of new materials}

In order to meet the requirements of strength, paste materials will be added with a certain proportion of Portland cement and other cementitious materials, and the cement cost accounts for $60 \sim 80 \%$ of filling costs (Wu et al., 2016). In recent years, new cementitious materials with low cost mainly have been developed, such as glue powder, fly ash, slag, red mud, sialite, etc. High-performance additives are also developed for different stages of performance, including flocculant, pumping agent, stabilizer, absorbent, early strength agent, retarder and so on.

Fly ash is an industrial waste discharged from thermal power plant, and is mainly composed of vitreous body containing a small amount of unburned carbon, part of quartz and mullite. Fly ash can be used as a substitute for cement because of its pozzolanic activity, but it often needs to be used in conjunction with exciting materials. On the other hand, its micro aggregate effect can improve the slurry flow and can be widely used in mine filling.

A large amount of vitreous exists in smelting slag whose activity depends on the ratio of $\mathrm{CaO} / \mathrm{SiO}_{2}$ in vitreous composition. Currently, the blast furnace slag without grinding and nickel and copper smelting slag are widely used as part of the filling aggregate in order to improve the activity and workability of filling slurry. For instance, they have been successfully used in Tonglushan Copper Mine, Huize Lead-zinc Mine and Zhangmatun Iron Mine for paste preparation.

$\mathrm{CH}$ hemihydrate phosphogypsum is a new gelled material being developed, which is mainly composed of calcium oxide, sulfur oxide (three), and crystalline water as well as a small amount of phosphorus, fluorine 
and organic compounds. The mineral composition of hemihydrate gypsum mainly includes burnt gypsum and a small amount of gypsum and quartz. The addition of hemihydrate phosphogypsum as cementitious materials can adjust paste condensation, while attaining lower bleeding rate and higher strength. Therefore, it can solve the problem of phosphor gypsum stacking and reduce the filling cost. This technology is rather promising in phosphorus chemical industry.

The new materials can fulfill specific functions at different filling stages, and have absolute advantages in reducing the filling cost, strengthening the filling quality and improving the filling efficiency. With their development still at an early stage in China, it has broad prospects of research and application (Cui and Sun, 2010; Zhu et al., 2011; Fu et al., 2011; Yan et al., 2016).

\subsection{Construction of engineering laboratory}

In 2016, the University of Science and Technology Beijing and the Institute of Integrity Mining Technology jointly built the first intelligent engineering laboratory in China. The laboratory includes the detection system of filling material, cyclone classification system, tailings thickening system, deep cone paste mixing system, multistage pump pressure loop experiment system and waste disposal system. It can simultaneously conduct fine unit experiments with industrial intelligent interlocking control. The platform can be used for both the basic research and process plan verification and industry standard setting. It is not only the first research platform of paste automation in China but also pioneering the technology in the world.

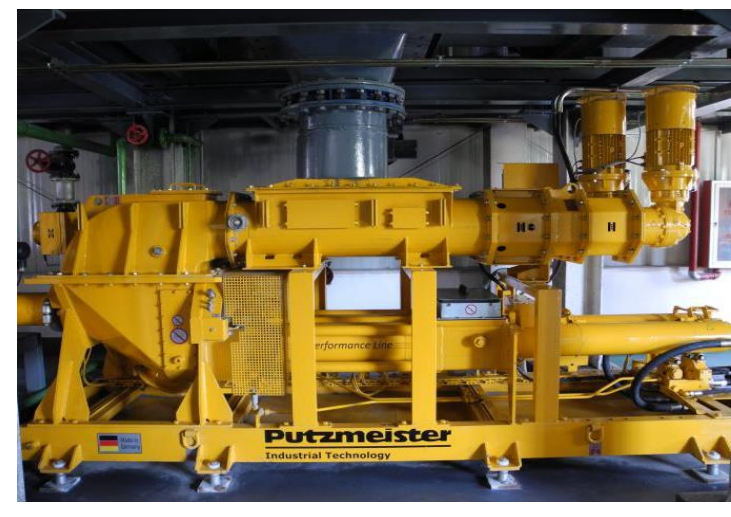

(a)

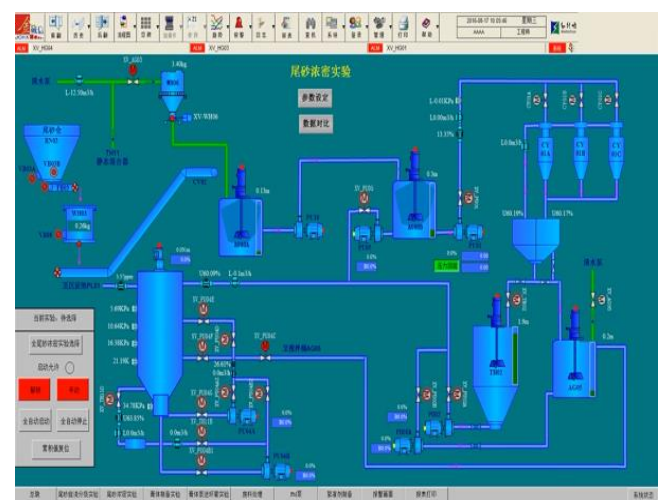

(b)

Figure 4 Diagram of paste backfill system in the intelligent engineering laboratory; (a) pumping equipment; (b) automatic control system

\section{$4 \quad$ Practices of paste technology in China}

\subsection{Paste filling practice in Huize Lead-zinc Mine}

Huize Lead-zinc Mine is one of the most popular high-grade lead-zinc mines around the world. The orebody is thick and the average grade is $30 \sim 40 \%$. Meanwhile, the deposit is located at Northeastern Yunnan province, on the west shore of the Niulan River and is within the National Water and Soil Conservation Key Prevention and Control Zone. Three sides of the deposit are surrounded by water, with a buried depth of $1600 \mathrm{~m}$. Furthermore, characteristics of high stress, fragile rock and poor stability of the deposit male it one of the most difficult deep mines in China.

The mine adopts the mechanized panel upward as well as downward drift mining method, which could avoid underground water bursting and decrease geostatic activity in deep mining. Meanwhile, the safety of mining operations can be ensured when issues such as rock burst are under control. The stoping rate is reported to reach $98.95 \%$ with only $6.5 \%$ of dilution (Ao et al., 2016).

The paste filling system in Huize Lead-zinc Mine, built in 2006, is the first implementation of tailings thickening 
by deep cone thickener in China. Using this system, the underflow concentration could reach 69 73\%. Meanwhile, the use of two-stage horizontal agitation and pump-gravity transportation arrives at a deepest transportation distance of $1600 \mathrm{~m}$ and a farthest transportation distance of $5468 \mathrm{~m}$, with the biggest stowing gradient being 4.14. The tail-waste ratio and cement-sand ratio are 9:1 and 1:10, respectively. Meanwhile, the paste slurry concentration is $80 \pm 1 \%$. To deal with the retardation of paste, $0.4 \sim 0.5 \%$ sodium sulfide was added in the slurry to enhance the coagulation properties. The test shows that the strength of paste curing for $28 \mathrm{~d}$ could reach 3 4 MPa. Furthermore, with poisonous ions having been absorbed, the underground bursting water also lives up to top groundwater environmental quality standard and groundwater quality standard.

\subsection{Paste deposition in Wushan Copper-Molybdenum Mine}

Wushan Copper-Molybdenum Mine, the fourth biggest copper-molybdenum associated deposits, is located in the center of the Hulun Buir Prairie, one of the three biggest prairies in the world. The deposit zone features a cold temperate climate with other issues such as water shortage, low precipitation and extremely cold winter (with a minimum temperature of $-43^{\circ} \mathrm{C}$ ).

Tailings was discharged by paste which was prepared in $\phi 40 \mathrm{~m}$ deep cone thickener. The feed concentration was approximately $28 \%$ while the underflow concentration could reach $70 \sim 72 \%$ and the flocculant dosage was $20 \mathrm{~g} / \mathrm{t}$. Four set diaphragm pumps were used for tailings transportation and the diameter of pipes was $324 \mathrm{~mm}$. The furthest transportation distance was reported to be $4.0 \mathrm{~km}$ with a daily tailings discharge capacity of 39,000 tons.

With an accumulation angle of roughly $3 \sim 5 \%$, the tailings slope ensured good fluidity and consolidation of paste in tailings discharge. No dust was found even on windy days. Backwater produced by paste discharge system could decrease water consumption by $6,600,000 \mathrm{t} / \mathrm{a}$ and lead to favourable economic and ecological benefits.

To ensure reliable tailings discharge in icy winter, the discharging technique under the frozen layer was proposed and applied, with the implementation of discharge, flow, consolidation and backwater of the paste implemented under ice. Other measures like adding plastic layers above pipes and electrical heating for heat preservation were carried out as well.

In a word, paste discharge technology could lead to better safety, ecological and economic benefits. The comparisons between paste discharge technology and traditional methods are listed in Table 1.

Table 1 Comparison of conventional wet discharge and paste discharge

\begin{tabular}{|c|c|c|}
\hline Project & Traditional discharge & Paste discharge \\
\hline Dam construction & Complex design and high cost & Simple and inexpensive \\
\hline Storage capacity & Low capacity for water storage required & Larger capacity for only floods \\
\hline Water conservation & Fast evaporation and poor backwater & More backwater and no seeper \\
\hline $\begin{array}{l}\text { Environmental } \\
\text { protection }\end{array}$ & Poisonous tailings with high permeability & Tailings consolidated quickly \\
\hline Safety assessment & $\begin{array}{c}\text { Dam's stability endangered by liquefaction caused } \\
\text { by vibration }\end{array}$ & No seepage causing dam break \\
\hline $\begin{array}{l}\text { Anti-seismic } \\
\text { property }\end{array}$ & Performed poorly & Performed well \\
\hline Closure of pit & 2 3 years spent for saturating slurry & $\begin{array}{c}\text { Only one year required before land } \\
\text { reclamation }\end{array}$ \\
\hline
\end{tabular}

\section{$5 \quad$ Future development of paste technology in China}

Paste technology has great prospects in the development of fundamental theories, process technologies, 
special equipment and material design. In particular, to solve issues such as deep mining, bulk preparation and cost control, paste technology needs to confront challenges including high temperature, strong stress, deep drilling, system stability, intelligent adjustment and regulation, as well as high cost. Studies regarding deep paste filling need to be carried out to achieve accurate control, homogeneous preparation, reliable transportation and safe recovery.

(1) Adaptive control of concentration

Concentration is a vital factor affecting the paste property. Therefore, adaptive control of concentration amounts to the nano-engineering for paste technology. The key to control paste properties is to develop an intelligent monitor and regulation system based on the combination of online monitoring and intelligent adaption system.

(2) Precise preparation of paste

Precise preparation ensures the desired performance of paste. It firstly involves changes in extensive control patterns of aggregates for further precise management. Secondly, the asymmetrical precise control should be implemented to ensure that technical parameters fluctuate within the reasonable range. The improvement of the precise control of equipment is necessary for system reliability in highly efficient running state.

(3) Tailored stope-filling design

According to various technical conditions, economical requirements and expected filling performances, filling designs for underground stopes can be tailored to provide flexible solutions which are adaptive to and demanded by actual conditions. Tailored filling design involves that of filling techniques, plans for different stopes and solutions for different zones in one stope. Furthermore, the paste filling system in the future should fit with the concept of "Industry 4.0" and take into account more customer demands in product design.

(4) $3 \mathrm{D}$ and modular

3D modular system design and assembly simulation by 3D design software could virtually reconstruct the paste filling system with low design risks. The modular system design could efficiently facilitate system assembly and operation. Meanwhile, grid-based disposal not only benefits tailored design for each unit, but also contributes to rapid assembly of the whole system, hence improving the efficiency and reliability of the system.

\section{Conclusions}

Paste technology achieves recycling utilization on solid wastes. It could effectively enhance the rate of supporting pit roof and minimize the strata movement. Backwater in front of the factory can recycle water. Safety issues and pollution of the tailings pond could be dealt with. In a word, paste technology has become one of the most popular subject areas in the mining industry, and will attract more attention in the future.

Paste technology is an interdisciplinary project. In China, a considerable amount of work has been carried out in tailings thickening, pipeline transportation, paste performances, development of new materials and laboratory construction. Until now, studies on paste technology have focused more on intelligent and precise control, with the main purposes being the precise preparation of well-performed paste, lower filling cost and reliable system operation.

The paste technology has been applied successfully in various mines in China, especially deep, rich-water, broken mines with high stress. However, tailings discharge is rarely applied, pointing to a huge potential market.

Studies and applications on paste technology are believed to achieve more progress with international 
cooperation and communication for better environment.

\section{References}

Ao, S.F., Cui, M.J., Shi, Z.L., Zhang, C.H., Zhang, X., Hong, W. and Chen, L.K. 2016, 'The industrial practice and application of resources comprehensive utilization technologies in Huize Lead-zinc Mine', China Mining Magazine, vol. 25, no. 11, pp. 102-106.

Chen, H.J. and Liu, Q.J. 2009, 'Harms and resource-like treatment of the solid wastes from metal mines', Metal Mine, no. 4, pp. 154156.

Chen, Y.G. and Zhang, K.N. 2005, 'Comprehensive treatment and application of solid waste of mines', Resources Environment and Engineering, no. 4, pp. 311-313.

Cui, Y., Pang, J.L. and Zhang, D. 2013, 'Optimization of mining pumping filling system for paste and paste-like', Journal of Liaoning Technical University (Natural Science Edition), no. 7, pp. 891-895.

Cui, Z.D. and Sun, H.H. 2010, 'The preparation and properties of coal gangue based sialite paste-like backfill material', Journal of China Coal Society, vol. 35, no. 6, pp. 896-899.

Fall, M., Célestin, J. and Sen, H.F. 2010, 'Potential use of densified polymer-pastefill mixture as waste containment barrier materials', Waste Management, vol. 30, no. 12, pp. 2570-2578.

Fu, C.H., Ni, W., Zhang, X.F., Wang, Z.J. and Tian, M.Y. 2011, 'Slag-fly ash based cementitious materials special for high performance concrete', Journal of University of Science and Technology Beijing, vol. 33, no. 5, pp. 606-613.

Ghirian, A. and Fall, M. 2013, 'Coupled thermo-hydro-mechanical-chemical behaviour of cemented paste backfill in column experiments. Part I: Physical, hydraulic and thermal processes and characteristics', Engineering Geology, pp. 195-207.

Jewell, R.J. and Fourie, A.B. 2002, 'Paste and Thickened Tailings - A Guide', Australian Centre for Geomechanics, Perth, pp. 2-30.

Ji, X.W. and Yan, Q.W. 2006, 'Technology research on cement backfilling based on unclassified tailings and water quenched slag in chihong company', Nonferrous Metals (Mine Section), no. 2, pp. 11-13.

Jiao, H.Z., Wu, A.X., Wang, H.J., Liu, X.H., Yang, S.K. and Xiao Y.T. 2011, 'Experiment study on the flocculation settlement characteristic of unclassified tailings', Journal of University of Science and Technology Beijing, no. 12, pp. 1437-1441.

Li, F.X. and Chen, Y.Z. 2009, 'Properties and microstructure of marine concrete with composite mineral admixture', Journal of Wuhan University of Technology-Materials Science Edition, vol. 24, no. 3, pp. 497-501.

Li, H.Q. and Fang, L.G. 2004, 'Investigation on the characteristics of paste pumping into the empty area and the reducing pumping resistance', Journal of Hunan University of Science and Technology (Natural Science Edition), vol. 19, no. 1, pp. 31-34.

Li, Y.B. 2004, 'Experimental study and application of paste pumping filling technology in mining area No.2 of Jinchuan Nickel Mine', Nonferrous Metals (Mine Section), no. 5, pp. 9-11.

Liu, Q.Q. 1998, 'LDV measurements and experimental study of water and sediment two phase flow', Journal of Sediment Research, no. 2, pp. 74-82.

Liu, T.Y. 2001, 'Technology and application on cut and fill mining', Metallurgical Industry Press, Beijing.

Lu, S.L. 2011, 'Research of world energy issues and China energy security', PhD thesis, Party School of the Central Committee of CPC, Beijing.

Qian, M.G., Miao, X.X., Xu, J.L. and Cao, S. 2008, 'On scientized mining', Journal of Mining and Safety Engineering, vol. 25, no. 1, pp. 1-10.

Ruan, Z.E. 2015, 'Numerical simulation of the flocculation and settling behavior of the whole-tailings particles in deep-cone thickener', Master thesis, University of Science and Technology Beijing, Beijing.

Wang, B. 2014, 'Research on the evaluation of green mining in China', PhD thesis, China University of Geosciences (Beijing), Beijing.

Wang, D.C., Yu, M.Z. and Wang, X.K. 2000, 'Experimental study on the particle motion in open channel flow', Journal of Basic Science and Engineering, no. 3, pp. 301-309.

Wang, G.Q. 1989, 'Theoretical and experimental study on the motion of solid-liquid two-phase flow and particle flow', PhD thesis, Tsinghua University, Beijing.

Wang, X.M., Gu, D.S. and Zhang, Q.L. 2010, 'Filling theory and pipeline transportation technology in deep mine', Central South University Press, Changsha.

Wang, Y., Wang, H.J. and Wu, A.X. 2011, 'Mathematical model of deep cone thickener underflow concentration based on the height 
to diameter ratio', Journal of Wuhan University of Technology, no. 8, pp. 113-117.

Wang, Y., Wu, A.X., Wang, H.J., Yang, X.X., Zhou, F.L. and Zhou, B. 2014, 'Further development of paste definition from the viewpoint of yield stress', Journal of University of Science and Technology Beijing, no. 7, pp. 855-860.

Wang, Y., Wu, A.X., Wang, H.J., Yin, S.H., Liu, H.J. and Kang, C.D. 2013, 'A method to determine deep cone thickener volume and its application', Journal of China University of Mining and Technology, no. 1, pp. 45-49.

Wu, A.X., Cheng, H.Y., Wang, Y.M., Wang, H.J., Liu, X.H. and Li G.C. 2016, 'Transport resistance characteristic of paste pipeline considering effect of wall slip', The Chinese Journal of Nonferrous Metals, no. 1, pp. 180-187.

Wu, A.X., Jiao, H.Z., Wang, H.J., Yang, S.K., Yao, G.H. and Liu, X.H. 2012, 'Mechanical model of scraper rake torque in deep-cone thickener', Journal of Central South University (Science and Technology), no. 4, pp. 1469-1474.

Wu, AX, Liu, X.H., Wang, H.J., Wang, Y.M., Jiao, H.Z. and Liu S.Z. 2014, 'Resistance characteristics of structure fluid backfilling slurry in pipeline transport', Journal of Central South University (Science and Technology), no. 12, pp. 4325-4330.

Wu, A.X. and Wang, H.J. 2015, 'Theory and technology of paste backfilling on metal ore', Science Press, Beijing.

Wu, A.X., Wang, Y. and Wang, H.J. 2016, 'Status and prospects of the paste backfill technology', Metal Mine, no. 7, pp. 1-9.

Wu, A.X., Wang, Y.M. and Wang, H.J. 2015, 'Estimation model for yield stress of fresh uncemented thickened tailings: Coupled effects of true solid density, bulk density, and solid concentration', International Journal of Mineral Processing, vol. 143, pp. 117-124.

Wu, A.X., Wang, Y.M., Wang, H.J., Ai, C.M., Zhou, B., Yang, X.X. and Zhou, F.L. 2014, 'Paste fill system designs for a broken and waterrich copper mine', in R.J. Jewell, A.B. Fourie, P.S. Wells and D. Van Zyl (eds), Proceedings of the 17th International Seminar on Paste and Thickened Tailings, Australian Centre for Geomechanics, Perth, pp. 654-655.

Wu, A.X., Wang, Y.M., Wang, H.J., Yin, S.H. and Miao, X.X. 2015, 'Coupled effects of cement type and water quality on the properties of cemented paste backfill', International Journal of Mineral Processing, vol. 143, pp. 65-71.

Wu, A.X., Yang, S.K., Wang, H.J., Jiao, H.Z. and Xiao, Y.T. 2011, 'Status and trend of paste disposal technology for superfine unclassified tailings', Mining Technology, no. 3, pp. 4-8.

Xie, H.P., Gao, F., Ju, Y., Ge, S.R., Wang, G.F., Zhang, R., Gao, M.Z., Wu, G. and Liu, J.Z. 2017, 'Theoretical and technological conception of the fluidization mining for deep coal resources', Journal of China Coal Society, vol. 42, no. 3, pp. 547-556.

Xu, Z.J., Hou, H.P., Zhang, S.L., Ding, Z.Y., Ma, C.Z., Gong, Y.L. and Liu, Y.J. 2012, 'Effects of mining activity and climatic change on ecological losses in coal mining areas', Transactions of the Chinese Society of Agricultural Engineering, vol. 28, no. 5, pp. $232-240$.

Yan, A.Y., Ni, W., Huang, X.Y., Zhang, J.W., Li, Y.Q. and Xu, D. 2016, 'Solidification/stabilization of $\mathrm{Pb}^{2+}$ within a blast furnace slag-steel slag based cementing agent for paste backfilling', Journal of University of Science and Technology Beijing, no. 7, pp. 899-905.

Yu, N.Z. 2016, 'Green mining and paste filling', Nonferrous Metals Design, no. 1, pp. 1-5.

Zeng, J.J., Shui, Z.H. and Wang, G.M. 2010, 'The early hydration and strength development of high-strength precast concrete with cement/metakaolin systems', Journal of Wuhan University of Technology- Materials Science Edition. vol. 25, no. 4, pp. $712-716$.

Zhang, D.S., Liu, H.L., Fan, G.W., and Wang, X.F. 2015, 'Connotation and prospection on scientific mining of large Xinjiang coal base', Journal of Mining and Safety Engineering, vol. 32, no. 1, pp. 1-6.

Zhu, L.P., Ni, W., Huang, D., Hui, M. and Gao, S.J. 2011, 'Whole-tailings backfilling materials with fly ash', Journal of University of Science and Technology Beijing, vol. 33, no. 10, pp. 1190-1196.

Zou, Y. 2016, 'Study on water hammer characteristics of solid-liquid mixture for coarse particle in pipe flow', Master thesis, Minzu University of China, Beijing. 